\title{
Efeitos de diferentes épocas de indução floral no desenvolvimento de frutos de abacaxizeiro 'Pérola' no norte do Tocantins
}

Diversos fatores podem interferir no ciclo da cultura do abacaxizeiro e na qualidade dos frutos produzidos, dentre esses os tratos culturais, principalmente no que se refere ao tratamento de indução floral. O período de colheita e a uniformização dos frutos podem ser regulados pelo uso de indutores florais. Dentro desse contexto, o trabalho teve como objetivo avaliar a influência da indução floral (IF) em diferentes dias após plantio (dap) sobre características de frutos de abacaxizeiro da cultivar Pérola cultivados no município de Araguatins/TO. O delineamento experimental foi em blocos casualizados. Os tratamentos consistiram de 4 épocas de IF (T1-305dap; T2-320dap; T3-335dap; T4-350dap) e 5 repetições. Foram avaliados a duração das fases entre o plantio à colheita, o teor de Sólidos Solúveis Totais (SST), Acidez Total Titulável (ATT), relação SST/ATT, peso de fruto com e sem coroa, diâmetro do fruto e produtividade. A fase compreendida entre indução-florescimento oscilou de 41 a 43 dias e do florescimento-colheita de 100 a 104 dias. 0 ciclo total da cultura variou de 450 a 492 dias. 0 peso de fruto com e sem coroa não sofreu interferência dos tratamentos, variando respectivamente, de 1.388 a $1.552 \mathrm{~g}$, e de 1.381 a $1.489 \mathrm{~g}$. Quanto às características químicas dos frutos, apenas o SST sofreu influência dos diferentes tratamentos, sendo que o T4 permitiu o desenvolvimento de frutos com ํㅏix mais elevado. A produtividade não foi influenciada pelos diferentes tratamentos e oscilou entre 39.413 e 44.794 kg.ha-1.

Palavras-chave: Indução Floral; Ananas comosus; Escalonamento; Produção; Manejo.

\section{Effects of different periods of floral induction on the development of 'Pérola' pineapple fruits in northern Tocantins}

\begin{abstract}
Several factors may interfere in the cycle of the pineapple crop and the quality of the fruits produced, among them the cultural treatments, especially with regard to the treatment of floral induction. The harvest period and the uniformity of the fruits can be regulated by the use of floral inducers. In this context, the objective of this work was to evaluate the influence of floral induction (FI) on different days after planting (dap) on the characteristics of pineapple fruits of the cultivar Pérola cultivated in the city of Araguatins/TO. The experimental design was in randomized blocks. The treatments consisted of 4 periods of FI (T1-305dap, T2320dap, T3- 335dap, T4-350dap) and 5 replicates. The duration of the phases between planting at harvest, Total Soluble Solids (TSS), Total Titratable Acid (TTA) TSS/TTA ratio, fruit weight with and without crown, fruit diameter and yield were evaluated. The phase comprised between induction-flowering ranged from 41 to 43 days and flowering-harvest from 100 to 104 days. The total culture cycle ranged from 450 to 492 days. The weight of fruit with and without crown was not affected by treatments, ranging from 1,388 to 1,552 g, and from 1,381 to $1,489 \mathrm{~g}$, respectively. As for the chemical characteristics of the fruits, only the TSS was influenced by the different treatments, and the T4 allowed the development of fruits with higher ${ }^{\circ} B r i x$. The productivity was not influenced by the different treatments and ranged from 39,413 to $44,794 \mathrm{~kg}$.ha- 1 .
\end{abstract}

Keywords: Floral induction; Ananas comosus; Scheduling; Production; Management.

Topic: Desenvolvimento, Sustentabilidade e Meio Ambiente

Reviewed anonymously in the process of blind peer.
Received: 04/09/2020

Approved: $10 / 11 / 2020$
Rafael Gomes da Mota Gonçalves (D)

Universidade Federal Rural do Rio de Janeiro, Brasil

http://lattes.cnpq.br/0244672026134100

http://orcid.org/0000-0001-9541-6698

rafaelmotag@hotmail.com

\section{Aline Gomes de Paula Sousa}

Companhia Nacional de Abastecimento, Brasil

http://lattes.cnpq.br/0609395099821182

gomesaline505@gmail.com

Tadeu Augusto van Tol de Castro

Universidade Federal Rural do Rio de Janeiro, Brasil

http://lattes.cnpq.br/6353947754324048

http://orcid.org/0000-0003-4095-3976

tadeuvantol@hotmail.com

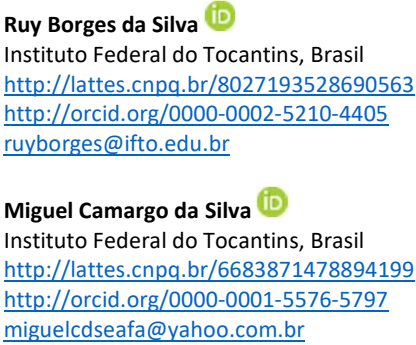

Referencing this:

GONÇALVES, R. G. M.; SOUSA, A. G. P.; CASTRO, T. A. V. T.; SILVA, R. B.; SILVA, M. C.. Efeitos de diferentes épocas de indução floral no desenvolvimento de frutos de abacaxizeiro 'Pérola' no norte do Tocantins. Nature and Conservation, v.13, n.4, p.84-92, 2020. DOI: http://doi.org/10.6008/CBPC2318-2881.2020.004.0010 


\section{INTRODUÇÃO}

A fruticultura é um dos setores de maior destaque na agricultura brasileira, envolvendo aproximadamente seis milhões de pessoas de forma direta e indireta, advindas de lavouras de pequeno, médio e grande porte. A área plantada é de aproximadamente 2,5 milhões de hectares. O Brasil é o terceiro maior produtor mundial de frutas, alcançando um rendimento de 40,9 milhões de toneladas (Anuário Brasileiro de Fruticultura). As principais espécies frutícolas em área plantada e volume de produção cultivadas no país são a banana, laranja, abacaxi, mamão e melancia (IBGE, 2017).

A produção de frutas obtém espaço em todos os estados brasileiros, porém em alguns, devido a suas condições favoráveis para o cultivo, o resultado é mais significativo. O Tocantins destaca-se na fruticultura em virtude dos recursos hídricos e da alta luminosidade. Nos últimos quatro anos, o estado do Tocantins aumentou aproximadamente $65 \%$ do volume produzido, atingindo 300 mil toneladas de frutas, com destaque para a produção de abacaxi Fachinello (2011). Segundo a Embrapa (2017), a região norte contribuiu com aproximadamente $25 \%$ da produção no país, numa área de 18,8 mil atingindo 90 milhões de toneladas.

O abacaxi (Ananas comosus L.) pertence à família bromeliácea, herbácea, perene e com altura variando de 1,0 a 1,2 m. A provável origem é a América do Sul, especificamente a região compreendida entre as zonas centrais e sul do Brasil e nordeste da Argentina. A temperatura ótima de cultivo situa-se na faixa de $22^{\circ} \mathrm{C}$ a $32^{\circ} \mathrm{C}$, e luminosidade 2.500 a 3.000 horas.ano ${ }^{-1}$. A inflorescência é constituída por um grupo de flores que se dispõem em torno de um eixo. As folhas do abacaxizeiro são classificadas em A, B, C, D, E e F de acordo com o formato e posição, iniciando da mais velha e externa para a mais nova e interna (REINHARDT et al., 2000). A propagação do abacaxizeiro pode ser vegetativa, por meio de mudas denominadas tipo filhote, filhote-rebentão e rebentão, além de mudas micropropagadas em laboratório (MATOS et al., 2009).

A cultivar de abacaxi 'pérola' é uma planta de porte ereto, apresentando coroa dos frutos grande, alta produção de mudas, frutos com formato semicônico, casca e polpa de coloração branca e acidez moderada. Uma das limitações dessa cultivar é a baixa resistência à fusariose e susceptibilidade a nematoides de lesões radiculares (RAMALHO et al., 2009).

As características físicas e químicas do fruto são de fundamental importância para a definição de técnicas de manejo pós-colheita, assim como para a boa aceitação do produto pelo consumidor. Essas características geralmente são influenciadas por fatores, como as condições edafoclimáticas, cultivar, época de colheita e tratos culturais. Para avaliar a qualidade dos frutos podem ser adotados diversos parâmetros químico-físicos, como peso, comprimento, diâmetro, forma, cor, firmeza, sólidos solúveis totais, pH, acidez titulável, entre outros (FAGUNDES et al., 2001).

O ciclo natural do abacaxizeiro pode ser influenciado pela época de plantio, tipo de muda, cultivar, tratos culturais e principalmente pelas condições climáticas. A floração natural dificulta a colheita dos frutos, levando a uma desuniformidade na produção, o que pode prejudicar a comercialização dos frutos (KIST, 2010).

Dentre os vários fatores que interferem no ciclo da cultura do abacaxizeiro e na qualidade dos frutos 
produzidos, destaca-se os tratos culturais, principalmente no que se refere ao tratamento de indução floral. Essa técnica permite, através do uso de indutores florais, uniformizar ou até mesmo antecipar a floração de modo que a produção ocorra de forma racional e se possa viabilizar a comercialização na época de preços favoráveis (KIST et al., 2011). Atualmente existem vários produtos eficientes na indução floral do abacaxizeiro, como o ethephon (2-cloroetilfosfônico), o carbureto de cálcio $\left(\mathrm{CaC}_{2}\right)$, etileno $\left(\mathrm{C}_{2} \mathrm{H}_{4}\right)$ e acetileno $\left(\mathrm{C}_{2} \mathrm{H}_{2}\right)$, entretanto, o ethephon é o indutor mais utilizado no Brasil, sendo um precursor do etileno (CARVALHO et al., 2009).

A escolha da melhor época para realizar a indução floral deve considerar o porte das plantas, as condições climáticas e o período com preços mais favoráveis para comercialização. Desta forma, o objetivo deste trabalho foi avaliar a influência das diferentes épocas de indução floral na produção e na qualidade dos frutos de abacaxi da cultivar pérola produzidos na mesorregião do Bico do Papagaio.

\section{MATERIAIS E MÉTODOS}

O experimento foi instalado no setor de fruticultura do Instituto Federal do Tocantins (IFTO) Campus Araguatins, localizado na latitude $05^{\circ} 44^{\prime} 31^{\prime \prime} \mathrm{S}$ e longitude $48^{\circ} 19^{\prime} 01^{\prime \prime} \mathrm{O}$, cultivando-se abacaxizeiro Pérola em área com solo classificado como Argissolo Vermelho Amarelo segundo o Sistema Brasileiro de Classificação de Solos (SIBCs). O clima é classificado como subúmido com pequena deficiência hídrica (C2rA'a'), caracterizando-se por evapotranspiração potencial média anual de $1.700 \mathrm{~mm}$ (SEPLAN, 2008). Na Tabela 1 são apresentados os resultados da análise de solo com amostras coletadas em profundidade de 0$20 \mathrm{~cm}$.

Tabela 1: Características físico-químicas do Argissolo Vermelho Amarelo.

\begin{tabular}{|c|c|c|c|c|c|c|c|c|c|c|}
\hline \multirow{2}{*}{$\mathrm{pH} \mathrm{em} \mathrm{H}_{2} \mathrm{O}$} & $\mathrm{P}$ & $\mathrm{K}$ & $\mathrm{Ca}$ & $\mathrm{Mg}$ & $\mathrm{Al}$ & $\mathrm{H}+\mathrm{Al}$ & $\mathrm{S}$ & $\mathrm{T}$ & $\mathrm{V}$ & M.O. \\
\hline & \multicolumn{2}{|c|}{ mg.dm-3 } & \multicolumn{4}{|c|}{$------\mathrm{cmol} \cdot \mathrm{dm}^{3}-----$} & & \multicolumn{3}{|c|}{$--\%--$} \\
\hline 6,3 & 11,0 & 305 & 12,5 & 3,2 & 0,0 & 3,63 & 16,48 & 20,11 & 81,95 & 3,06 \\
\hline \multicolumn{11}{|c|}{ Características físicas (Granulometria) } \\
\hline Areia & & & & Argila & & & Silte & & & \\
\hline \multicolumn{11}{|c|}{$--------------\%-------------$} \\
\hline 20,9 & & & & 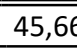 & & & 33,44 & & & \\
\hline
\end{tabular}

Os dados climáticos do período de avaliação no município de Araguatins estão apresentados nos gráficos 1 e 2.

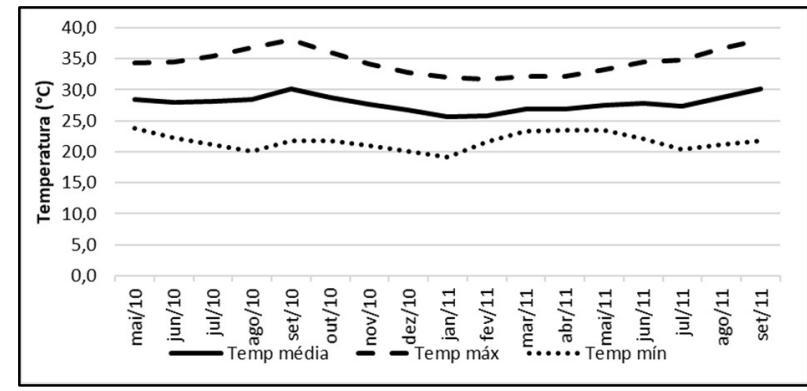

Gráfico 1: Temperaturas $\left({ }^{\circ} \mathrm{C}\right)$ observadas durante o período de avaliação da cultura.

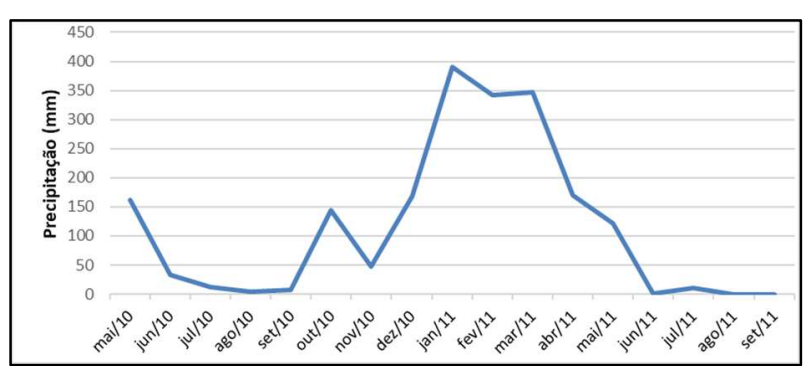

Gráfico 2: Precipitações $(\mathrm{mm})$ observadas durante o ciclo da cultura. 
As mudas utilizadas para o plantio foram do tipo filhote, plantadas em sulcos em fileiras duplas com espaçamento $1,5 \times 0,40 \times 0,35 \mathrm{~m}$. Foi realizada adubação de fundação com superfosfato triplo na dose de 10 g.cova ${ }^{-1}$. O calendário de adubação de cobertura é mostrado na Tabela 2.

Tabela 2: Calendário de adubação de cobertura para a cultura do abacaxi.

\begin{tabular}{lll}
\hline \multirow{2}{*}{ Épocas } & \multicolumn{2}{c}{ Dose por planta (g.planta-1) } \\
\cline { 2 - 3 } $1^{\circ}$ Cobertura: Novembro (Início das chuvas) & $\mathrm{N}$ & $\mathrm{K} 2 \mathrm{O}$ \\
$2^{\circ}$ Cobertura: Dezembro (30 dias após a primeira) & 4,4 & 3 \\
$3^{\circ}$ Cobertura: Fevereiro (60 dias após a segunda) & 4,4 & --- \\
\hline \hline
\end{tabular}

O controle das ervas daninhas foi realizado inicialmente com a utilização de cobertura morta. Posteriormente, utilizou-se a capina química com o herbicida Krovar (diuron + bromacil) na dosagem de 4 kg.ha ${ }^{-1}$ o que permitiu um controle eficiente das ervas daninhas.

Utilizou-se o delineamento experimental em blocos casualizados, com quatro tratamentos e cinco repetições. Cada parcela foi constituída por quatro fileiras, cada uma com 20 plantas, sendo as duas fileiras centrais a área útil contendo 40 plantas e as fileiras laterais a bordadura.

Os tratamentos foram constituídos por diferentes épocas de indução floral, aos quais foram aplicados $50 \mathrm{~mL}$ por planta de solução de ethephon a 1.000 ppm, aos 305 dap - dias após plantio - (T1); 320 dap (T2); 335 dap (T3); e 350 dap (T4). As aplicações do indutor floral foram realizadas a partir das 17:00 horas. Foi avaliado o número de dias entre o plantio, a indução floral, o florescimento e a colheita. No momento em que a infrutescência começou a emergir foram marcadas aleatoriamente 10 plantas por parcela.

Os frutos foram protegidos dos raios solares com o uso de papel jornal, conforme é observado na Figura 1. A colheita foi realizada quando os frutos apresentaram o terço basal da casca amarelado e mensurou-se o comprimento e peso do fruto com e sem coroa, diâmetro mediano do fruto, teor de sólidos solúveis totais (SST), acidez total titulável (ATT) do suco, pelos métodos da AOAC (1990), e relação SST/AT.

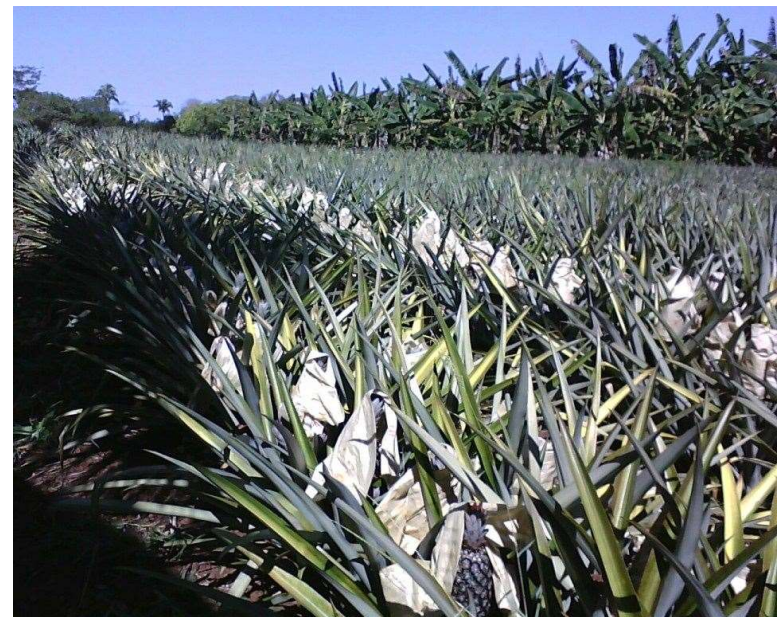

Figura 1: Proteção dos frutos para controle da queima solar.

O controle da broca dos frutos (Thecla basalides) foi realizado quinzenalmente, no período do início do florescimento até fechamento das flores, sendo utilizada a aplicação de $50 \mathrm{Ml}^{\text {.planta-1 }}{ }^{-1}$ de uma calda de $50 \mathrm{~mL}$ de Decis $+200 \mathrm{~mL}$ de óleo mineral diluídos em 20 litros d'água. 
Os dados obtidos foram submetidos à análise de variância, complementada pelo teste de Tukey. As análises estatísticas foram realizadas por meio do software Assistat (SILVA, 2011).

\section{RESULTADOS E DISCUSSÃO}

Os tratamentos de indução floral (TIF) permitiram que o surgimento da inflorescência ocorresse de forma uniforme nos diferentes tratamentos (Figura 2), em intervalos que variaram de 41 dias a 43 dias (Tabela 3). A fase compreendida entre o florescimento e a colheita oscilou de 100 a 104 dias, totalizando um período 142 a 147 dias da indução à colheita.

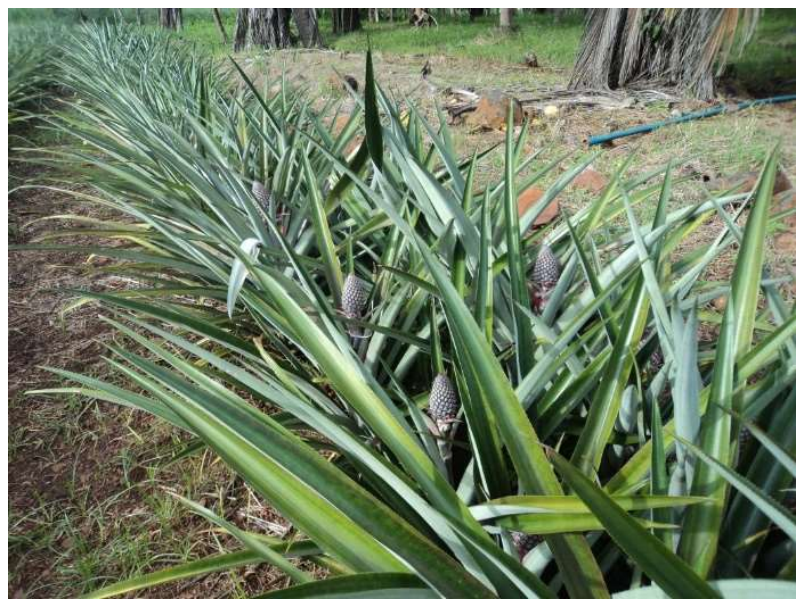

Figura 2: Uniformidade na emissão da inflorescência de uma parcela experimental.

O ciclo total da cultura variou de 450 a 492 dias e o escalonamento da colheita apresentou intervalo de 13 dias entre o primeiro e segundo TIF, enquanto que entre o segundo e terceiro TIF foi ampliado para 19 dias.

Tabela 3: Número de dias do plantio à indução floral (IF), da indução ao surgimento das inflorescências, do florescimento à colheita, da indução à colheita e do plantio à colheita, de plantas de abacaxizeiro 'Pérola' submetido a diferentes épocas de indução floral.

\begin{tabular}{lllll}
\hline \multirow{2}{*}{ Épocas de IF (dias após plantio) } & $\begin{array}{l}\text { Indução - florescimento } \\
\text { Dias }\end{array}$ & Florescimento - colheita & Indução - colheita & Plantio - colheita \\
\hline T1 -305 & 41 & 104 & 145 & 450 \\
T2 -320 & 42 & 101 & 143 & 463 \\
T3 -335 & 43 & 104 & 147 & 482 \\
T4 -350 & 42 & 100 & 142 & 492 \\
\hline
\end{tabular}

Verifica-se que não houve variações expressivas na duração das fases de florescimento e frutificação, mesmo registrando-se mudanças nas condições climáticas, como elevação de temperatura, redução da umidade do ar e das precipitações (Figura 3).

Na maioria das regiões produtoras de abacaxi do Brasil a colheita dos frutos ocorre entre cinco meses e meio e seis meses após a data da indução floral, com exceção do sul do país, onde ocorrem temperaturas mais baixas, esse período pode ser um pouco mais prolongado (CUNHA et al., 2004).

Carvalho et al. (2005) avaliando o efeito de diferentes épocas de indução em abacaxizeiro 'perola' na região sul do Brasil, observaram que as fases da indução-florescimento, indução-colheita e ciclo total foram, respectivamente, em média, de 87, 150 e 827 dias. Este aumento nas fases do ciclo da cultura decorre das 
baixas temperaturas presente na região sul do país. Inversamente, o Tocantins, devido à baixa latitude apresenta segundo Santos et al. (2009) maior incidência da radiação solar global e insolação, principalmente nos meses de abril a setembro.

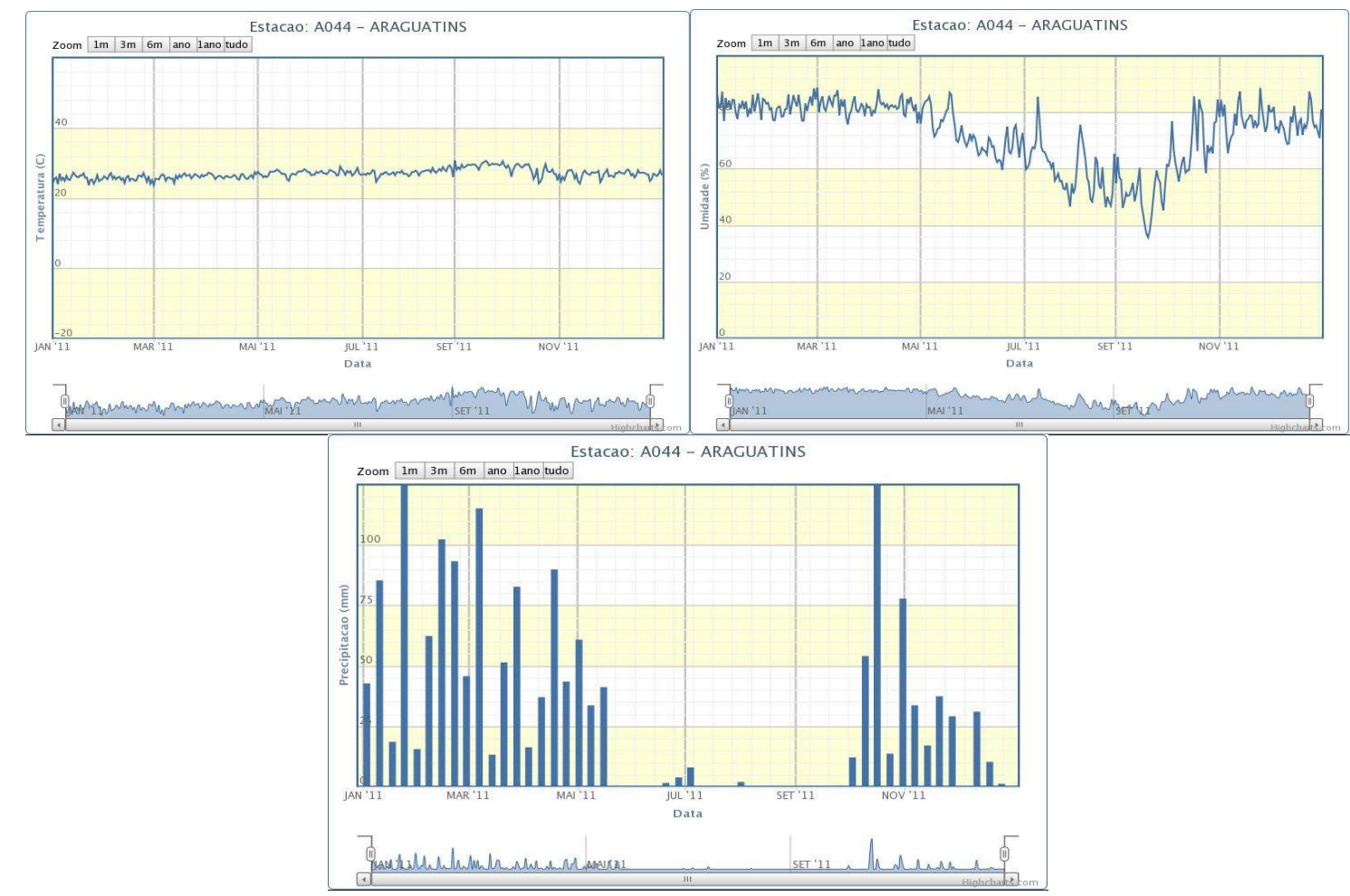

Figura 3: Dados climáticos do município de Araguatins durante a fase de frutificação. Fonte: INMET (2015).

Na Tabela 4 tem-se os teores de sólidos solúveis totais (SST), acidez total titulável (ATT) e a Relação SST/ATT dos frutos. Observa-se que as diferentes épocas de TIF interferiram apenas no teor de SST, sendo que o T4 proporcionou a produção de frutos com Brix mais elevado. O desenvolvimento dos frutos durante o período de maior temperatura foi um dos fatores que explica este resultado. Segundo Bleinroth (2000), a ocorrência de temperaturas mais elevadas durante o desenvolvimento dos frutos proporciona maior síntese de açúcares e/ou degradação de ácidos. O teor de SST encontrados nos frutos satisfazem ao padrão de comercialização mínimo exigido pelo Ministério da Agricultura que estabelece o teor de $12^{\circ} \mathrm{Brix}$.

Tabela 4: Sólidos Solúveis Totais (SST), Acidez Total Titulável (ATT), Relação SST/ATT de frutos do abacaxizeiro 'Pérola' submetido a diferentes períodos de indução floral (IF).

\begin{tabular}{llll}
\hline Épocas de IF (dias após plantio) & SST ( ${ }^{\circ}$ Brix) & ATT (\% de ácido cítrico) & SST/ATT \\
\hline T1-305 & $14,1 \mathrm{a}^{*}$ & $0,5 \mathrm{a}$ & $30 \mathrm{a}$ \\
T2 -320 & $14,0 \mathrm{a}$ & $0,6 \mathrm{a}$ & $23 \mathrm{a}$ \\
$\mathrm{T} 3-335$ & $14,4 \mathrm{a}$ & $0,6 \mathrm{a}$ & $23 \mathrm{a}$ \\
T4 -350 & $16,0 \mathrm{a}$ & $0,6 \mathrm{a}$ & $25 \mathrm{a}$ \\
\hline
\end{tabular}

* Médias seguidas pela mesma letra na coluna não diferem entre si pelo teste de Tukey, a 5\% de probabilidade.

Avaliando a qualidade dos frutos de abacaxi comercializados na cooperativa Cooperfruto em Miranorte/TO, Pereira et al. (2009) verificaram que os teores de sólidos solúveis se apresentaram na faixa de $12,4-15,7^{\circ}$ Brix. Quanto à acidez titulável total (ATT), os frutos apresentaram teores de 0,5 a $0,6 \%$, estes valores são compatíveis com os valores encontrados $(0,35$ a 0,65) por Pereira et al. (2009). Os teores aceitáveis estão compreendidos entre 0,40\% e 1,00\% (CUNHA et al., 2004). 
A relação SST/ATT está compreendida entre 23 e 30, indicando uma boa qualidade dos frutos para o consumo in natura. Segundo Pereira et al. (2009) os frutos produzidos na região de Miracema apresentam uma relação entre 20,3 a 40,4. O balanço entre ${ }^{\circ}$ Brix e acidez dos frutos, representado por SST/ATT, tem sido comumente utilizado para avaliar o sabor dos frutos (CUNHA et al, 1999).

$\mathrm{Na}$ Tabela 5 são apresentados os valores de peso, comprimento e diâmetros dos frutos. O peso dos frutos com coroa variou de 1.388 a 1.552 gramas, e sem coroa variou de 1.311 a 1.489 gramas, estando de acordo com os valores encontrados por Pereira et al. (2009) que foram de 1.335 a $1.772 \mathrm{~g}$ para fruto com coroa 1.145 a $1.1566 \mathrm{~g}$ fruto sem coroa.

Os frutos produzidos no Tocantins apresentam peso superior aos frutos produzidos em outros estados brasileiros. Provavelmente, isto resulta da alta disponibilidade de luminosidade e não das menores densidades de plantio adotadas. De acordo com dados de Cunha et al. (1999) diversos trabalhos mostram que o aumento da população de plantas por área não influenciou no peso dos frutos.

Dentre os parâmetros físicos mostrados na Tabela 5, apenas o comprimento do fruto com coroa e sem coroa foram influenciados pelos diferentes períodos de IF, sendo que o tratamento 1 permitiu o melhor desenvolvimento dos frutos, apresentando respectivamente, valores médios de $32,8 \mathrm{~cm}$ e $24,1 \mathrm{~cm}$. Provavelmente, este resultado pode ser atribuído ao desenvolvimento do fruto no período de maior precipitação.

Tabela 5: Parâmetros físicos do fruto de abacaxi, comprimento do fruto com e sem coroa, diâmetro de frutos.

\begin{tabular}{|c|c|c|c|c|c|}
\hline $\begin{array}{l}\text { Épocas de IF } \\
\text { (Dias após plantio) }\end{array}$ & Peso do fruto + coroa & $\begin{array}{l}\text { Peso do fruto } \\
\mathrm{Kg}\end{array}$ & $\begin{array}{l}\text { Comp. fruto + coroa } \\
-\end{array}$ & Comp. fruto & Diâmetro do fruto \\
\hline $\mathrm{T} 1-305$ & $1.534 \mathrm{a}^{*}$ & $1.465 \mathrm{a}$ & $32,8 \mathrm{a}$ & $24,1 \mathrm{a}$ & 9,9 a \\
\hline $\mathrm{T} 2-320$ & $1.552 \mathrm{a}$ & $1.489 \mathrm{a}$ & $30,1 \mathrm{~b}$ & $22,8 \mathrm{ab}$ & $10,1 \mathrm{a}$ \\
\hline T3 - 335 & $1.430 \mathrm{a}$ & $1.381 \mathrm{a}$ & $28,4 \mathrm{C}$ & $22,0 \mathrm{ab}$ & $10,0 \mathrm{a}$ \\
\hline $\mathrm{T} 4-350$ & $1.388 \mathrm{a}$ & $1.311 \mathrm{a}$ & $29,5 \mathrm{~b}$ & $20,8 \mathrm{~b}$ & $10,1 \mathrm{a}$ \\
\hline
\end{tabular}

* Médias seguidas pela mesma letra na coluna não diferem entre si pelo teste de Tukey, a $5 \%$ de probabilidade.

Na avaliação do diâmetro mediano do fruto observou-se valores entre 9,9 e 10,1 cm, sendo que estes concordam com os dados encontrados por Pereira et al. (2009). De acordo com Pereira et al. (2009) os frutos de abacaxi 'pérola' do Tocantins apresentam maior tamanho em relação aos frutos produzidos nos demais estados do País. Isto é confirmado pelos resultados obtidos por Franco (2010) em Janaúba-MG, sendo que o comprimento médio do fruto com e sem coroa foram de 24,9 e $13,8 \mathrm{~cm}$, respectivamente, valores bem inferiores aos observados na Tabela 5.

Na tabela 6 verifica-se a produtividade de frutos do abacaxizeiro 'pérola' submetido a diferentes épocas de IF. As produtividades observadas não foram influenciadas pelos diferentes tratamentos e oscilaram entre 39.413 e 44.794 kg.ha ${ }^{-1}$.

Tabela 6: Produtividade de frutos do abacaxizeiro 'Pérola' submetido a diferentes épocas de indução floral.

\begin{tabular}{ll}
\hline Épocas de IF (dias após plantio) & Produtividade (kg.ha-1) \\
\hline T1-305 & $44.045 \mathrm{a}$ \\
T2 -320 & $44.794 \mathrm{a}$ \\
T3 -335 & $41.529 \mathrm{a}$ \\
T4 -350 & $39.413 \mathrm{a}$ \\
\hline
\end{tabular}

* Médias seguidas pela mesma letra na coluna não diferem entre si pelo teste de Tukey, a 5\% de probabilidade. 
Não foi observada diferença significativa entre os tratamentos de IF para a variável produtividade, oscilando entre 39.413 e 44.794 kg.ha-1 ${ }^{-1}$ Os valores de produtividade consideraram uma população de 30.075 plantas por hectare. Segundo Matos et al. (2014) a população média adotada no Tocantins é de aproximadamente 28.000 plantas por hectare, enquanto que Cunha et al. (1999) cita que nos demais Estados está população varia de 20 mil a 75 mil plantas por hectare.

\section{CONCLUSÕES}

O tratamento de indução floral proporciona uniformização do surgimento da inflorescência.

O alto índice de radiação solar associado altas temperaturas e pluviosidade favoreceu a redução no ciclo da cultura quando comparado a outras regiões produtoras. A duração das fases compreendida entre indução-florescimento foi 41 e 43 dias, enquanto que do florescimento-colheita variou de 100 a 104 dias.

Apenas o SST sofreu influência dos diferentes tratamentos, sendo que o T4 permitiu o desenvolvimento de frutos com Brix mais elevado. Dentre as características físicas, apenas o comprimento do fruto com e sem coroa sofreram interferência dos diferentes tratamentos.

Não houve interferência das diferentes épocas de indução floral na qualidade química dos frutos. Os frutos de todos os tratamentos apresentam elevada qualidade para consumo "in natura", com teores adequados de SST (\%) e ATT (\%).

AGRADECIMENTOS: Ao Instituto Federal do Tocantins pelo apoio financeiro e implantação do experimento, à CAPES e a Universidade Federal Rural do Rio de Janeiro.

\section{REFERÊNCIAS}

AOAC. Association of Official Agricultural Chemists. Official methods of analysis of the association of the agricultural chemistry. 15 ed. Washington: AOAC, 1990.

BLEINROTH, E. W.. Frutas Tropicais: 2: Abacaxi. Campinas: Secretaria de Agricultura do Estado de São Paulo ITAL, 2000.

CARVALHO, C. A. L.. Tópicos em Ciências Agrárias. Cruz das Almas: Universidade Federal do Recôncavo da Bahia, 2009.

CARVALHO, S. L. C.. Épocas de indução floral e soma térmica do período do florescimento à colheita de abacaxi 'Smooth cayenne'. Revista Brasileira de Fruticultura, Jaboticabal, v. 27 n.3, p.430-433, 2005. DOI: https://doi.org/10.1590/S0100-29452005000300022

CUNHA, G. A. P.; CABRAL, J. R. S.; SOUZA, L. F.. 0 abacaxizeiro: cultivo, agroindústria e economia. Brasília: Embrapa Comunicação para Transferência de Tecnologia, 1999.

CUNHA, G. A. P.; SANCHES, N. F.; MEDINA, V. M.. Abacaxi: o produtor pergunta, a Embrapa responde. Brasília: EMBRAPASPI, 2004.
EMBRAPA. Empresa Brasileira de Pesquisa Agropecuária. Produção brasileira de abacaxi em 2017. Embrapa Mandioca e Fruticultura, 2017.

FACHINELLO, J. C.; PASA, M. S.; SCHMTIZ, J. D.; BETEMPS, D. L.. Situação e perspectivas da fruticultura de clima temperado no Brasil. Revista Brasileira de Fruticultura, Jaboticabal, p.109-120, 2011.

FAGUNDES, G. R.; YAMANISHI, O. K.. Características físicas e químicas de frutos de mamoeiro do grupo 'Solo' comercializados em 4 estabelecimentos de Brasília/DF. Revista Brasileira de Fruticultura, Jaboticabal, v.23, n.3, 2001.

FRANCO, L. R. L.. Crescimento, produção e qualidade do abacaxizeiro 'Pérola' sob diferentes lâminas de irrigação por gotejamento. Monografia (Bacharelado) -Universidade Estadual de Montes Claro, Montes Claro, 2010.

IBGE. Instituto Brasileiro de Geografia e Estatística. Censo agropecuário: lavoura permanente e temporária. Rio Janeiro: IBGE, 2017.

INMET. Instituto Nacional de Meteorologia. BDMEP: Banco de Dados Meteorológicos para Ensino e Pesquisa. INMET, 2015. 
KIST, H. G. K.; RAMOS, J. D.; SANTOS, V. A.; RUFINI, J. C. M. Fenologia e escalonamento da produção do abacaxizeiro 'Smooth Cayenne' no Cerrado de Mato Grosso. Brasília: Pesquisa agropecuária brasileira, 2011.

KIST, H. G. K.. Manejo da floração visando o escalonamento da produção do abacaxizeiro no Serrado Mato-grossense. Tese (Doutorado em Produção vegetal) - Universidade Federal de Lavras, Lavras, 2010.

MATOS, A. P.; VASCONCELOS, J. A. R.; SIMÃO, A. H.; PEREIRA, A. O.; GOMES, D. C.; TEIXEIRA, F. A.; QUEIROZ, G. B.; TAVARES, I. A.; MAGALHÃES, M. M. S.; SANCHES, N. F.; COSTA, P. G.. Práticas de cultivo para a cultura do abacaxi no Estado do Tocantins. Cruz das Almas: Embrapa, 2014.

MATOS, A. P.; VASCONCELOS, J. A. R.; SIMÃO, A. H.; PEREIRA, A. O.; GOMES, D. C.; TEIXEIRA, F. A.; QUEIROZ, G. B.; TAVARES, I. A.; MAGALHÃES, M. M. S.; SANCHES, N. F.; COSTA, P. G.. Circular técnica 89: Produção de Mudas Sadias de Abacaxi. Cruz das Almas: EMBRAPA, 2009.

PEREIRA, M. A. B.; SIEBENEICHLER, S. C.; LORENÇONI, L.; ADORIAN, G. C.; SILVA, J. C.; GARCIA, R. B. M.; BRITO, R. F. F.
Qualidade do fruto de abacaxi comercializado pela Cooperfruto, Miranorte/TO. Revista Brasileira de Fruticultura, Jaboticabal, v.31, n.4, p.1048-1053, 2009.

RAMALHO, A. R.; VIEIRA JUNIOR, J. R.; FERNANDES, C. F.; ROCHA, R. B.; MARCOLAN, A. L.; CASSARO, J. D. Comunicado técnico 349: Características das cultivares de abacaxizeiros cultivados no Estado de Rondônia. Porto Velho: Embrapa, 2009.

REINHARDT, D. H.. Abacaxi. Produção: aspectos técnicos; Embrapa Mandioca e Fruticultura. Brasília: Embrapa Comunicação para Transferência de Tecnologia, 2000.

SANTOS, D. M.. Variabilidade temporal da radiação solar e insolação no município de Araguaína/TO. Revista RAEGA Curitiba, n.18, p.35-40, 2009

SEPLAN. Secretaria do Planejamento e Meio Ambiente/Tocantins, Diretoria de zoneamento ecológicoeconômico. Atlas do Tocantins: Subsídios ao planejamento da gestão territorial. Palmas: SEPLAN, 2008.

SILVA, F. A. S.. ASSISTAT. Versão 7.6 beta. DEAG-CTRNUFCG. 2011.

A CBPC - Companhia Brasileira de Produção Científica (CNPJ: 11.221.422/0001-03) detém os direitos materiais desta publicação. Os direitos referem-se à publicação do trabalho em qualquer parte do mundo, incluindo os direitos às renovações, expansões e disseminações da contribuição, bem como outros direitos subsidiários. Todos os trabalhos publicados eletronicamente poderão posteriormente ser publicados em coletâneas impressas sob coordenação da Sustenere Publishing, da Companhia Brasileira de Produção Científica e seus parceiros autorizados. Os (as) autores (as) preservam os direitos autorais, mas não têm permissão para a publicação da contribuição em outro meio, impresso ou digital, em português ou em tradução. 